\title{
La noción de ley de Gabriel Vázquez de Belmonte
}

The concept of law in Gabriel Vázquez de Belmonte

Cintia Faraco

Universidad de Nápoles, Italia cintia.faraco@unina.it

DOI: https://doi.org/10.15366/bp2021.26.012

Bajo Palabra. II Época. No26. Pgs: 239-254 
Recibido: 20-08-2020

Aceptado: 10-09-2020

\section{Resumen}

El presente ensayo tiene el objetivo de poner de relieve la visión filosófico-jurídico-política que se puede extraer de la lectura de la obra vazqueciana. El tema de la ley se trata precisamente en la disputatio 150 del Commentariorum, ac disputationum in primam secundae S. Thomae, que se subdivide en cuatro capítulos cuyo objetivo es aclarar la personal visión del autor.

Palabras clave: Ley, acciones, ley humana, regla moral, ley natural secundaria, conciencia, ley natural primaria, suapte natura.

\section{Abstract}

The present essay has the objective of highlighting the philosophical-legal-political vision that can be extracted from the reading of the Vazquecian work. The subject of the law is dealt with precisely in the disputatio 150 of the Commentariorum, ac disputationum in primam secundae S. Thomae, which is subdivided into four chapters whose objective is to clarify the personal vision of the author.

Keywords: Law, actions, human law, moral rule, secondary natural law, conscience, primary natural law, suapte natura. 


\section{Premisa: primeras definiciones}

GABRIEl VÁzQUeZ ${ }^{1}$, ya CONOCIDO POR SUS CONTEMPORÁNeOS por la elegancia retórica de sus argumentaciones, tuvo modo de interrogarse sobre su concepto de ley en varias ocasiones durante sus cursos romanos (1585-1591) y complutenses (1591-1604) orientados hacia la exégesis de la Summa Theologiae de Santo Tomás de Aquino, como se requería en aquellos tiempos. El presente ensayo tiene el objetivo de poner de relieve la visión filosófico-jurídico-política que se puede extraer de la lectura de la obra vazqueciana. El tema de la ley se trata precisamente en la disputatio 150 del Commentariorum, ac disputationum in primam secundae $S$. Thomae ${ }^{2}$, que se subdivide en cuatro capítulos cuyo objetivo es aclarar la personal visión del autor. Ésta va precedida por la nueva proposición de la quaestio 90 de la Summa Theologiae y por una notatio, en la cual el jesuita subraya que el tema de la ley va encuadrado bajo dos aspectos: "in argumento" e "in corpore" ${ }^{3}$ y afirma que la ley debe considerarse "opus rationis, an voluntatis"

Más exactamente "Lex opus est intellectus, non voluntatis, est autem opus intellectus, sicut imperium supponens actum voluntatis, nempe est propositio, quam Scholastici intimationem vocant voluntatis superioris"s: la mera voluntad, aunque sea de un superior, no tiene fuerza de $\mathrm{ley}^{6}$, de hecho, Dios "non tamen vult, sed etiam praecipit" 7 .

\footnotetext{
${ }^{1}$ Gabriel Vázquez (18 de junio de 1549 en Villaescusa de Haro-23/30 de septiembre de 1604 en Alcalá). En 1569 entró en la Compañía de Jesús y durante sus estudios fue discípulo del dominico Domingo Báńez. Brillante rector y finísimo teólogo, enseñó durante mucho tiempo también en el Collegio Romano donde estuvo desde 1585 hasta 1591, donde su fama creció de manera exponencial, tanto que el papa Benedicto XIV lo definió, en su obra De Synodo diocesana, "Luz de la Teología". Cfr. Astrain, A., La historia de la Compañía de Jesús en la asistencia de España, Madrid, Administración de Razón y Fe, 1913, tomo IV, pp. 318-323; Castro, C., Vida inédita del P. Gabriel Vázquez, ed. ATG 37 (1974), pp. 227-244; Sygut, M., Natura e origine della potestà dei vescovi nel Concilio di Trento e nella dottrina successiva, Roma, PUG, 1998.

2 Vázquez, G. Commentariorum, ac disputationum in primam secundae S. Thomae, tomus secundus, Compluti, ex Officina Iusti Sanchez Crespo, 1605.

3 «Conclusio est affirmans, quam probat $S$. Thomas tum in argumento, sed contra, quia praecipere est actus rationis; tum etiam in corpore quia lex est regula humanarum actionum et ratio, quia rationis est ordinare in finem, qui est homini principium operandi: ergo lex est aliquid pertinens ad rationem»: ibid. p. 4.

${ }^{4}$ Vázquez, G., Commentariorum, ac disputationum in primam secundae S. Thomae, II, op. cit., d. 150, notatio, p. 5.

5 Ibid., n. 16, p. 8.

${ }^{6}$ Ídem: «ergo sola voluntas superioris non habet vim legis».

7 Ídem. El método lógico-argumentativo hasta aquel momento enseñado en las scholae que establecía un desarrollo según opiniones opuestas será modificado: Vázquez procede con la idea de lograr una reconstrucción armónica
} 
Esto supone que la ley es propiamente un "imperium, et iussio superioris" y que "imperare autem, et iubere, sicut etiam orare, proprium est intellectus" ${ }^{8}$. En otros términos, a juicio de Vázquez, significa que, si Dios necesitara simplemente querer para ordenar algo, entonces Dios mismo ha querido, y por lo tanto ordenado, la muerte de su propio $\mathrm{Hijo}^{9}$, pero esto es imposible dado que el intelecto repudia lo que no es racional ${ }^{10}$.

La ley, por lo tanto, es un acto intelectual y, en su acepción de lex naturalis que es totalmente idéntica al ius naturale, dicha ley es "regula naturalis, quae nulla voluntate, sed suapte natura constat" ${ }^{11}$.

Esto supone que la naturaleza misma de las cosas, suapte natura, no implica nunca contradicción: antes de cualquier acto de voluntad o de intelecto, la regla de las acciones se haya en su naturaleza misma. En un ser racional, el bien, y por tanto el buen hacer, no implica nunca contradicción, mientras que el mal es la disonancia y la contradicción.

"Prima igitur lex naturalis in creatura rationali est ipsamet natura, quatenus rationalis, quia haec est prima regula boni, et mali" ${ }^{12}$; y, "Est igitur lex naturalis in nobis primarie ipsa natura rationalis, secundarie autem per modum applicationis potius est in iudicio, quam in imperio" ${ }^{13}$.

\section{La ley como regula bumanarum actionum: la conscientia o lex naturalis secundaria}

De todo Lo Dicho en el parágrafo anterior se desprende que para hablar de ley en el pensamiento de Gabriel Vázquez hay que partir de la definición de lex est regula humanarum actionum y considerar la ley natural bajo dos aspectos o niveles de explicación de la obligación moral interiore: la lex naturalis secundaria o conscientia y la lex naturalis primaria o suapte natura.

de las diferentes opiniones en apoyo de su propia posición, para poder relacionar idealmente la notatio con los capítulos centrales de la disputatio. Téngase en cuenta que desde finales del siglo XV el método había sido canonizado en el De loci theologicis de Melchor Cano.

8 Ídem, donde se cita la referencia a la disputatio 49, c. III del primer tomo. cfr. Vázquez, G. Commentariorum, ac disputationum in primam secundae S. Thomae, tomus primus, Compluti, ex Officina Ioannis Gratiani, 1614, d. 49 , c. III, n. 5 , p. 305.

9 "Ut si alicui praeciperet occidere filium, posset de morte illius, non ea ratione, qua praecepta est, sed alia». Vázquez, G., Commentariorum, ac disputationum in primam secundae S. Thomae, II, op. cit., d. 150, n. 17, p. 8.

${ }^{10}$ En este punto cfr. Tessarolo, G., La nozione di soddisfazione e la necessità dell'incarnazione presso Gabriele Vasquez, Romae, PUG, 1942. En este texto se analiza entre otras cosas el concepto de justicia y de la salvación debida a Cristo.

${ }^{11}$ Ibid., c. III, n. 22, p. 10.

12 Ídem.

${ }^{13}$ Ibid., c. IV, n. 31, p. 12. 
Hay un primer nivel llamado lex naturalis primaria, que es el de la regula a priori, es decir, el de la naturaleza racional del hombre, que Vázquez describe varias veces como suapte natura, de la cual ya hemos hablado, y un segundo nivel denominado lex naturalis secundaria, que es el de la regula a posteriori, fruto de un juicio de la razón ${ }^{14}$.

Para comprender más fácilmente estos dos niveles es oportuno empezar por el segundo, o sea, de la conciencia, ya que el juicio de dicha conciencia y la ley son un unicum.

En el esquema argumentativo vazqueciano, de hecho, la conciencia es la regla más próxima a la actuación humana ${ }^{15} \mathrm{y}$ su papel es el de transmitir fuerza vinculante a nuestra acción ${ }^{16}$, como si esta última estuviera vinculada a un precepto.

Mejor dicho, la conciencia no constituye nunca un precepto especial, sino un precepto ya existente y que, precisamente por eso, encuentra aplicación. En esta perspectiva se podría decir que, en razón del acto, la conciencia se distingue en "antecedente y consecuente". Ésta es, en otros términos, ya sea un juicio moral sobre los actos que hay que cumplir, y en eso sería antecedente, ya sea un juicio moral sobre los actos ya cumplidos, y en este caso sería consecuente ${ }^{17}$.

En razón de la obligación, la conciencia puede definirse praecipiens, vetans, y consulens $^{18} \mathrm{y}$, bajo este aspecto, la conciencia desempeña la función específica de dar instrucciones, de prohibir o de aconsejar.

En razón de ser conforme a la ley, la conciencia puede definirse verdadera o errónea. Si es verdadera, la conciencia no puede ser otra cosa que la regla moral próxima de la acción, y ni siquiera Dios puede eximir al hombre de seguirla, porque, para el

\footnotetext{
${ }_{14}$ Sobre la existencia de un doble nivel de explicación de la obligación moral y, por consiguiente, de la ley natural, todos concuerdan con la interpretación de Gabriel Vázquez. De todos los estudiosos pongo como ejemplo el pensamiento de Fellermeier, que se había planteado el problema precisamente de la natura rationalis y compara dos fragmentos del texto de Vázquez para obtener precisamente la presencia de los citados niveles de ley: «Ostendimus, primam legem, et regulam naturalem esse ipsam naturam rationalem, per cuius convenientiam, aut inconvenientiam opera nostra examinanda, et expendenda sunt; proxima tamen est iudicium rationis nostrae», Vázquez, G., Commentariorum, ac disputationum in primam secundae S. Thomae, II, op. cit., q. 91, a. 2, explicatio, n. 7, p. 26; «nulla virtus, aut praeceptum obligat, nisi media conscientia, quae (ut diximus) est proxima regula nostrarum actionum», Vázquez, G., Commentariorum, ac disputationum in primam secundae $S$. Thomae, I, op. cit., d. 59, c. III, n. 11, p. 383.

${ }^{15} \mathrm{Al}$ contrario de la ley eterna, que si se pudiera considerar autónomamente existente en el pensamiento vazqueciano, se debería considerar la más remota y lejana.

${ }^{16}$ Cfr. Fellermeier, J., Das Obligationsprinzip bei Gabriel Vazquez, Roma, Scuola Salesiana del Libro, 1939, p. 29: «Das Gewissen übersetzt nur sozusagen das objektive Geboten oder Verboten sein, das mit dem Gesetze schon gegeben ist, in das subjektive Müssen oder Nichtdürfen».

${ }_{17}$ Cfr. Slovák, J., De conscientia morali apud Gabrielem Vazquez S.I., Romae, PUL, 1971, p. 35. Cfr. Vázquez, G., Commentariorum, ac disputationum in primam secundae S. Thomae, I, op. cit., d. 58, c. II, n. 9, p. 378.

${ }^{18}$ Cfr. ídem, Vázquez, G., Commentariorum, ac disputationum in primam secundae S. Thomae, I, op. cit., d. 58, c. I, n. 3, p. 376.
} 
jesuita, Dios no puede dispensar al hombre de seguir la ley natural ${ }^{19}$. Si es errónea, al contrario, se debe distinguir si el error, en el que ha caído la conciencia, procede de la ignorantia invicibilis o de la vincibilis. Solamente en el primer caso, es decir de un juicio fruto de una insuperable ignorancia, se puede considerar que el sujeto agente es excusable ${ }^{20} \mathrm{y}$, por lo tanto, no ha pecado ${ }^{21}$. Esto significa que quien ha efectuado en estas condiciones una acción, ha realizado una evaluación de los pocos elementos a su disposición, no pudiendo incluir de ninguna manera los que no estaban a su alcance. En todos los demás casos, la ignorantia es un error gravísimo y, por eso, según Vázquez no excusable.

En definitiva, si de la obra vazqueciana se pone de manifiesto que la conciencia, por un lado, es el elemento de unión entre la función práctica y la especulativa del intelecto, y por el otro lado, representa un juicio vinculante, desempeñando la función de lex naturalis secundaria, es asimismo verificable la falta de una explicación del contacto entre lo sensible y lo abstracto a través de la conciencia; explicación necesaria para justificar el paso del dictamen de la conciencia al acto.

También es verdad que el juicio de la conciencia representa, quizás, el elemento más cercano a la sensibilidad, pero la conciencia misma no es un elemento sensible, ni tampoco es esa energía sinérgica del cuerpo y la mente que, sin duda alguna, un racionalismo más moderado habría tenido en consideración.

\section{La ley como regula bumanarum actionum: suapte natura o lex naturalis primaria}

EN ESTE PUNTO DE LA INVESTIGACión ha llegado el momento de hacer hincapié en el concepto específico de ley y, en particular, de centrar la atención sobre lo que ha querido decir Vázquez con las expresiones lex naturalis primaria y suapte natura. Para hacerlo correctamente es útil volver al inicio de la notatio al art. 1, q. 90, I-II de Santo Tomás, donde el jesuita afirma: "lex est regula humanarum actionum, regula autem humanarum actionum est ratio, quia rationis est ordinare in finem, qui est homini principium operandi: ergo lex est aliquid pertinens ad rationem" 22 .

${ }_{19}$ Más exactamente, para el jesuita Dios no puede intervenir aportando modificaciones a la ley natural. Cfr. Vázquez, G., Commentariorum, ac disputationum in primam secundae S. Thomae, I, op. cit., d. 61, c. II, nn. 5-8, pp. 388-389.

${ }^{20}$ Cfr. ibid., d. 60, c. II, nn. 4-8, pp. 384-386.

${ }^{21}$ En mérito al concepto de pecado aquí señalado, me remito más específicamente a Faraco, C., Suapte natura. L'intrinseca forma razionale della natura: Gabriel Vázquez, Milano, FrancoAngeli, 2017, pp. 85-94.

22 Vázquez, G., Commentariorum, ac disputationum in primam secundae S. Thomae, II, op. cit., q. 90, a. 1, notatio, n. 1 , p. 4. 
La ley debe ser algo que atañe a la razón, ya que solo la razón ordina ad finem y, a su vez, es el principio según el cual el hombre debería obrar. Más detalladamente, la ley es un acto del intelecto, que se identifica en el imperium, que, a su vez, "sicut imperium supponens actum voluntatis, nempe est propositio, quam Scholastici intimationem vocant voluntatsi superioris" ${ }^{23}$.

La lex naturalis hunde sus raíces en la esencia divina ${ }^{24}$ de manera exclusiva, en cuanto Dios precede a todos los seres creados, y la lex naturalis primaria obedece a la esencia de dicho Dios como primer origen y causa, en la medida en que Él está exento de contradicciones internas. De esto deriva que la naturaleza misma sea racional, sea la fuente que origina al hombre, como creatura racional, y comparte, por ello, la misma esencia ${ }^{25}$.

La ley natural es la naturaleza racional del hombre, entendida como regla primaria de la propia obra moral; por lo tanto, ley natural y naturaleza racional coinciden. A su vez, la naturaleza racional se puede contemplar bajo un doble perfil: de por síy en cuanto no implica contradicción. Estas dos caras de la misma medalla son la base de los actos humanos ${ }^{26}$.

Esto significa que la ley natural existe independientemente del legislador, que podría promulgarla, modificarla o abolirla, y que tiene como objeto exclusivamente lo que ya está determinado, creado, ordenado, vigente ${ }^{27}$.

La ley es de por sí un acto de razón, pero difícilmente el acto que precede a la elección se puede definir como un juicio o un consejo; este acto de razón es por tanto solo una propuesta y una indicación dada al inferior por voluntad del superior ${ }^{28}$.

La ley natural no debe su existencia a la voluntad de nadie que no sea su propia naturaleza -suapte natura- y Dios, casi obligado ${ }^{29}$ a tal naturaleza, no puede con el propio libre albedrío modificar la ley natural.

\footnotetext{
23 Ibid., d. 150, c. II, n. 16, p. 8.

${ }^{24}$ Cfr. ibid., p. 30.

25 Cfr. ibid., p. 31.

${ }^{26}$ Cfr. Cruz Cruz, J., La esencia humana como regla autónoma del obrar moral, según Vázquez (s. XVI), en «Persona y Derecho: Revista de fundamentación de las Instituciones Jurídicas y de Derechos Humanos», 2013/2, vol. 6., p. 105.

27 Lo que en el "reino de lo posible" no está incluido.

${ }^{28}$ Cfr. Cruz Cruz, J., La esencia humana como regla autónoma del obrar moral, según Vázquez (s. XVI), op. cit., pp. 107-108.

29 Uso aquí el término "obligado" para hacer más eficaz la idea de un ser divino casi imposibilitado para decidir algo diferente de la lógica de no contradicción interior, solicitando así, por el contrario, la mente al vínculo con la crítica que llevó a Duns Scoto al racionalismo moderado de Tomás de Aquino y que, en el contexto vazqueciano, tomaría todavía más fuerza. Cfr. sobre el tema de la crítica Scoto-Tomás: Todisco, O. Liberare la verità. Duns Scoto all'assalto della prigione di Dio, en "Giornale di metafisica» Ser. NS, vol. 30 (2008), pp. 143-172.
} 
No se puede, a estas alturas, no mencionar el concepto de lex aeterna. El tema, no analizado de manera específica por Vázquez, casi como si lo considerara una especie de duplicado de la ley natural ${ }^{30}$, puede ser reconducido, como subraya Todescan, a la manera con la cual el jesuita plantea el problema del tiempo y de la eternidad.

Este planteamiento conduce a la idea de que la ley eterna, o mejor dicho la eternidad, es una simple precedencia respecto a los demás seres creados, para los cuales el tiempo aparecería 'espacializado' ${ }^{31}$.

Es la única ley natural que posee el prius absoluto, mientras que la lex aeterna, aun en superioridad ontológica, se vacía de sentido y de significado. Esto nos lleva a sostener que Vázquez no considera la ley eterna como regula et mensura actuum según el esquema del Aquinate, sino un modelo ideal según el cual Dios ha creado el universo ${ }^{32}$.

En la visión de Vázquez, la ley natural es autónoma y precedente a todo el acto racional de Dios "lex naturalis est ipsamet natura rationalis, ut rationalis est, quatenus ex se non implicat contradictionem: cum igitur hoc non habeat natura, ut rationalis, est, ex voluntate aut iudicio Dei, sequitur hoc modo non posse derivari a lege aeterna eo modo accepta" 33 .

El jesuita, atribuyendo al intelecto práctico la capacidad de juzgar siempre en línea con los primeros principios y de adaptarlos de alguna manera a la realidad a través de un lento proceso de alejamiento de estos -el procedimiento de adherencia a la realidad garantizado según Vázquez por la presencia de la conciencia-implica una rigidez en la concepción de la validez de las conclusiones de la ley natural. Se trata de una rigidez que no se ajusta perfectamente a las exigencias multiformes de la realidad ${ }^{34}$.

${ }_{30}$ Cfr. Todescan, F., Lex, natura, beatitudo, Padova, Cedam, 2014, pp. 291-295.

${ }^{31}$ Cfr. ibid., p. 291.

${ }^{32}$ Cfr. ibid., p. 292. En este sentido léase también Garssen, H., Die Naturrechtslehre des Gabriel Vasquez, Göttingen, 1951, pp. 43-44. Hasta Vázquez, todas las leyes derivaban de la ley eterna, en cuanto se consideraban participantes de la recta ley divina. De esta manera, como defendía Cruz Cruz «todo acto racional humano (...) precisamente en la medida en que es recto, está ya previamente realizado en Dios, cuyo saber es previo a cualquier otro saber, y solamente de Dios recibe el hombre la luz de la razón»: Cruz Cruz, J., La esencia humana como regla autónoma del obrar moral, según Vázquez (s. XVI), op. cit., p. 120.

${ }^{33}$ Vázquez, G., Commentariorum, ac disputationum in primam secundae S. Thomae, II, op. cit., q. 93, a. 3, explicatio, nn. 3-4, p. 42. Esto supone, en tema de promulgación que, como correctamente interpretado por Todescan, «la ley eterna no puede ser promulgada frente a súbditos que están constitutivamente inmersos en el tiempo, "nulla enim aeterna promulgatio esse potuit"; ya que la promulgación se refiere a la essentia legis, ni seguiría la inadmisibilidad de una ley eterna (...) dentro del esquema general de la lex"” Todescan, F., Lex, natura, beatitudo, op. cit., p. 292.

${ }^{34}$ Es precisamente Garssen quien pone en evidencia la aporía representada por la rigidez con la cual Vázquez teoriza una validez totalmente inmutable de la ley natural con la realidad cotidiana, que el jesuita tendrá que atenuar a través de la scientia. Cfr. Garssen, H., Die Naturrechtslehre des Gabriel Vasquez, op. cit., p. 55 e pp. 59-60. 
En la óptica recién descrita el bien y el mal se califican como tales en relación con una regla que se desprende del siguiente párrafo: "quaedam harum actionum quae suapte natura constet, sicut res omnes suapte natura contradictionem non implicant" ${ }^{35}$; tal regla se aplica toda "ante omne imperium, ante omne voluntatem, imo ante omne iudicium fit regula" 36 y la consecuencia es que "haec [regula] autem non potest alia esse, quam ipsamet rationalis natura ex se non implicans contradictionem" ${ }^{37}$.

Por otra parte, es el mismo Vázquez el que afirma que la autoridad proviene de Dios y lo mismo podemos decir de las instituciones; por consiguiente, rebelarse al orden de Dios significa exponerse a su condena ${ }^{38}$.

Vázquez, sin embargo, es consciente de haber "encerrado" en una jaula la ley natural, es decir, de haber concedido una inmovilidad tal que amordaza la estructura inicial de la ley natural, así como la había ideado Santo Tomás y, como subraya Cruz Cruz, el jesuita intenta remediar dicha rigidez hablando de dos tipos de modificabilidad de la ley. «Desde un punto de vista "formal" permanece la validez estricta de las normas naturales, y con ello también de las conclusiones, en cada caso; pero no así cuando es modificado el objecto o materia de la acción pertinente al precepto natural. Pues bien, una acción cae bajo un precepto de la ley natural si hay determinadas circunstancias especiales o necesarias; pero si estas faltan, entonces la norma no se refiere a ese caso» ${ }^{39}$.

Vázquez sostiene que Dios es la causa de la ley, ya que es causa eficiente con el atribuir existencia. Sin embargo, Dios da la vida, la existencia, pero no atribuye a las cosas la esencia (cf. Fellermeier, J., Das Obligationsprinzip bei Gabriel Vazquez, p. 12). Esto no implica contradicción de la acción divina, sino simplemente falta de juicio o de voluntad divina con respecto a las cosas posibles. Esta conclusión que deriva directamente del supuesto de la valoración de la moralidad de algunas acciones es una realidad que prescinde de la voluntad y del intelecto de Dios - en el texto, de hecho, se lee claramente: "notandum est [...] rerum omnium creaturarum naturas possibiles, hoc est, quae in se non implicant contradictionem non habere hoc ex iudicio aut voluntate", vid. Vázquez, Commentariorum ac disputationum in I-II, I, d. 97, c. III, n. 9, p. 619 y d. 97, c. I, n. 2, p. 617-.

\footnotetext{
35 Vázquez, G., Commentariorum, ac disputationum in primam secundae S. Thomae, II, op. cit., d. 150, c. III, n. 23, p. 10. Claramente la frase «regula quaedam harum actionum» sugiere la q. 90, I-II, de Tomás, pero a diferencia de esta, todos los términos giran en torno a la expresión, repetida varias veces, "suapte natura".

36 Ídem.

37 Ídem.

${ }^{38}$ Cfr. ibid., p. 43. Luego, me parece sostenible que a tal propósito el derecho del Estado sea un derecho natural, acercando así a Vázquez a la visión de Paolo di Tarso. Si el Aquinate había previsto dinamismo en la ley natural, una parte consistente de la segunda escolástica, y Vázquez in primis, prefirió una interpretación estática de la misma.

39 Ídem.
} 
Dios no muda la naturaleza de las cosas, sino que observa incluso lo que está mal, aunque no interviene para cambiar la esencia. Esto significa que "cumque nulla prohibitio indicans posset esse prior ipsa scientia, et cognitione Dei, fit necessario, ut nullum peccatum eo sit peccatum, quia prohibitione etiam indicante prohibitum sit" (Vázquez, Commentariorum ac disputationum in I-II, II, d. 97, c. I, n. 2, p. 617).

Si existe algo que discrimine entre el bien y el mal, hay que buscarlo no en la observación de Dios como Creador, sino mirando a la creatura y a los medios de que está dotada para estar en el mundo, aparte de al mundo del cual la creatura-hombre forma parte.

Es, quizás, por este motivo que Vázquez parecería afirmar que, siendo la norma de naturaleza no otra cosa que "rationalis natura ex se non implicans contradictionem" ${ }^{40}$, esta natura rationalis es interior a la propia naturaleza y guía la conducta moral del hombre.

De hecho, Vázquez no pretende eliminar a Dios como legislador, sino convertirlo en la causa de la existencia de las cosas, no de sus esencias, dando a entender con esto que la naturaleza racional del hombre es la misma que se encuentra en la ley natural ${ }^{41}$.

Tomando prestadas las palabras de Cruz Cruz, la ley, antes de ser natural, es precisamente "el conjunto de exigencias radicales o estructurales de la naturaleza humana como tal, o sea, biológica y racional a la vez. De modo que, en sentido estricto, ella no es una "ley", un precepto racional, sino algo previo: es el fundamento estructural de las leyes y preceptos racionales. Afirmaba que "la ley natural no se incluye en mandato ni en juicio alguno, sino que debe ser algo anterior a toda intelección y volición. Otros grandes maestros de su tiempo (como Domingo de Soto o Francisco Suárez) habían enseñado que la ley natural es formalmente un acto del entendimiento, una especie de "mandato", praeceptum o imperio racional»" ${ }^{42}$.

\section{La lex bumana}

Se hace hincapié aHora en la Ley humana, para lo cual hay que observar de nuevo la ley natural y en especial la relación entre las dos leyes ideada por Vázquez.

\footnotetext{
${ }^{40}$ Vázquez, G., Commentariorum, ac disputationum in primam secundae S. Thomae, II, d. 150, c. III, n. 23, p. 10. Cfr. Jakob Fellermeier, Das Obligationsprinzip bei Gabriel Vazquez, op. cit., p. 13.

${ }^{41}$ Cfr. Cruz Cruz, J., La esencia humana como regla autónoma del obrar moral, según Vázquez (s. XVI), op. cit., p. 114.

${ }^{42}$ Ibid., pp. 103-104.
} 
Como ya se ha dicho, la ley natural es una moral del ser, es decir, el ser de Dios, ya que se basa en Él. Esto pone en evidencia la falta de la ley eterna, que, en las doctrinas anteriores a la obra vazqueciana, era no solo el fundamento ontológico de la ley humana, sino también la esencia última del vínculo entre las leyes. Para recuperar el nexo entre la ley natural y la ley humana, Vázquez sostiene que hay una analogía entre las dos leyes, precisamente en consideración del fundamento que él atribuye a la moral.

Como la ley natural es una moral del ser de Dios, la ley humana es una moral del ser humano superior, es decir, es la moral de la autoridad ${ }^{43}$. El superior no es tal porque lo ha elegido Dios, sino, al contrario, porque es la manifestación exterior de un orden, en el cual el cuerpo está sometido a la cabeza, exactamente igual que la naturaleza está sometida a su Creador.

No es un error, por tanto, creer que Vázquez adopte una visión organicista y naturalista del Estado, en el cual el deber de obediencia de los súbditos se basa en el dicho principio según el cual los miembros de un cuerpo subyacen a la cabeza ${ }^{44}$.

Este superior, mediante la manifestación de su voluntad a los inferiores, ordena los medios para alcanzar el fin digno de ser perseguido y su acción de mando debe ser conforme a la honestidad y no debe sobrepasar los límites del poder del cual ha sido investido ${ }^{45}$. En este sentido el superior está sujeto a las disposiciones de la ley moral y a las normas que disciplinan al grupo social. En realidad, el legislador es "esclavo" de sus propias leyes ${ }^{46}$.

Análogamente a la acción de Dios-legislador, el hombre-legislador establece el praeceptum, le otorga existencia, comunicándolo a los inferiores, pero no dispone ni la medida ni el alcance que queda establecido en la misma naturaleza racional.

Para el jesuita, el legislador no tiene ningún efecto sobre la magnitud de la obligación, pero determina su existencia ${ }^{47}$. No atribuye, porque no puede atribuir, la esencial de dicho praeceptum ${ }^{48}$.

Cruz Cruz subraya eficazmente que Vázquez «Con el nombre de ley en sentido estricto entiende precisamente sólo la orden de un legislador, el mandato de un superior, dado además por escrito, dirigido a una pluralidad indeterminada de personas. En tal sentido, "ley" es la ley positiva, la cual presupone un acto espiritual

${ }_{43}$ Cfr. Vereecke, L., Conscience morale et loi humaine selon Gabriel Vazquez s.j., Tournai, Desclée \&Co Ed., 1957, p. 48.

${ }^{44}$ Cfr. Todescan, F., Lex, natura, beatitudo, op. cit., p. 170

${ }^{45}$ Cfr. Vereecke, L., Conscience morale et loi humaine, op. cit., p. 52.

${ }^{46}$ Cfr. Fellermeier, J., Begriff und Verpflichtung des positiven Gesetzes bei Gabriel Vazquez, en «Scholastik», 1940, p. 569

${ }^{47}$ Cfr. Vereecke, L., Conscience morale et loi humaine, op. cit., p. 77.

${ }^{48}$ Cfr. ibid., p. 78. 
de leer y elegir (legere, eligere); mas la ley natural es para él como la regla de lo justo e injusto, de lo malo y lo bueno, el fundamento inmutable de toda legislación positiva» ${ }^{49}$. Y, sobre todo, afirma que "Vázquez va más lejos y pretende derivar de la naturaleza humana la obligatoriedad misma de la ley natural, sin tomar en cuenta la voluntad divina» ${ }^{50}$.

Estas observaciones iluminan con nitidez cómo la concepción vazqueciana de la naturaleza de la ley humana está determinada claramente por la posición de la ley natural y cómo de esta última se derivan las primeras conclusiones que obligan en conciencia. Tales conclusiones o principios se identifican perfectamente en las normas del Decálogo, que son la exteriorización en la ley humana de la lex naturalis. Sin embargo, el derecho positivo se diferencia netamente de la ley de naturaleza.

Por una parte, la ley de naturaleza tiene una dimensión perfectamente ontológica y habita en la naturaleza racional del hombre, así que es moralmente bueno lo que corresponde a la naturaleza racional del mismo, y es moralmente malo lo que la contradice ${ }^{51}$. Por otra parte, la lex positiva parecería acentuar el carácter "psicológico", ya que psicológico es el acto que da vida al derecho positivo $^{52}$.

Así pues, hemos vuelto a hablar del imperium. Para Vázquez, el derecho positivo es un acto de mando que encuentra su forma y esencia en el intelecto junto a la objetiva posición de superioridad que ocupa quien manda ${ }^{53}$. El acto que da vida a la lex humana es, por tanto, un acto de intelecto, que prevé como supuesto "prerrequisito" un acto de voluntad.

El campo de la ley humana es esencialmente el campo del acto libre. Solo gracias a eso, Vázquez puede decir que una ley, que deriva, como resultado final de su transvase en ella, de la ley natural, no es una constitución humana, sino una simple declaración del derecho natural ${ }^{54}$.

Esto significa también que, por ejemplo, la bondad y la amabilidad del obrar natural de un hombre no se tienen que confundir con una acción, en realidad, obligada por una norma cualquiera, que, por lo tanto, elimina la espontaneidad ${ }^{55}$.

\footnotetext{
${ }^{49}$ Cruz Cruz, J., La esencia humana como regla autónoma del obrar moral, según Vázquez (s. XVI), op. cit., p. 124.

50 Ibid., p. 125. Esta posición es la más peculiar del Siglo de Oro y es la que abre el mundo filosófico a la interpretación moderna de la ley natural. Cfr. Cathrein, V., Moralphilosophie, Herder Friburgo de Brisgovia, 1911, I Band, 5B, 1.

${ }^{51}$ Cfr. Fellermeier, J., Begriff und Verpflichtung des positiven Gesetzes bei Gabriel Vazquez, op. cit., p. 560.

52 Cfr. ibid., p. 561.

53 Cfr. ibid., p. 562.

${ }^{54}$ Cfr. Vereecke, L., Conscience morale et loi humaine selon Gabriel Vazquez s.j., op. cit., p. 50.

55 Cfr. Ídem.
} 
La ley, para ser tal, ya sea naturalis o humana, debe incluir dos elementos: la prescripción del modo y su ejecución. Se trata, evidentemente, de una interpretación tomista, ya que, formalmente, la ley consiste en la indicación del modo de fijación de los medios y en el fin deseado ${ }^{56}$.

Planteada la cuestión en estos términos, no solo la lex naturalis, sino también la ley humana se resuelve formalmente en la prescripción de una manera a seguir, en un camino a seguir: quien dice prescripción, dice mandato. La ley será antes que nada un mandato, luego, se vuelve a proponer un imperium.

Para decirlo con las palabras de Vázquez "imperium autem est expressio desiderii tamquam superioris volentis ut aliquid fiat ab inferiori, cui insinuatur tale desiderium. Totum autem hoc recte explicatur per verbum imperandi: Fac hoc, sic enim denotamus non tantum voluntatem et desiderium ut illud fiat, sed etiam voluntatem tamquam superioris" ${ }^{37}$. En otros términos, se trata de llevar a cabo la voluntad del superior, en cuanto tal.

Cualquier ley humana, en la interpretación vazqueciana, obliga en conciencia, porque participa de la ley natural, primera norma de la actividad humana, pero esto podría significar que, en el caso en el cual un superior dé vida a una norma contraria a la exigencia de la naturaleza humana, dicha norma tendría que ser respetada. Si es evidente que un semejante mando no puede considerarse una ley, ni puede obli$\operatorname{gar}^{58}$, es igualmente obvio que nos encontramos ante una contradicción, porque la ley natural no puede aprobar y condenar al mismo tiempo, y bajo el mismo aspecto, dicho acto.

La solución a tal antinomia la identifica una vez más Vázquez en la recta razón, que guía nuestra vida; de hecho, reconociendo el buen camino en la no contradicción lógica interna de los mandos, juzga y comprueba - a posteriori- la presencia del error lógico en el acto ordenado.

Una vez más, y quizás todavía más significativo en el acto-ley humano ${ }^{59}$, el papel de la voluntad es objetivamente menor, por no decir inexistente, porque la voluntad no es esencial ni en el acto del mando ni en el poder que el mando expresa.

En este sentido se puede considerar ley solo "el mandato emitido por el jefe de una comunidad política, ya que la ley es la manifestación pública de una decisión, tomada por la autoridad del Estado, dirigida a los ciudadanos, expresada con

\footnotetext{
56 Cfr. ibid., p. 51.

57 Vázquez, G., Commentariorum, ac disputationum in primam secundae S. Thomae, I, op. cit., d. 49, c. III, n. 14, p. 307.

58 Cfr. Vereecke, L., Conscience morale et loi humaine selon Gabriel Vazquez s.j., op. cit., p. 54.

59 Para profundizar sobre el tema me remito a Faraco, C., Suapte natura, op. cit. centrado en el tema del acto y de la acción y, con ello, del imperium.
} 
fórmulas solemnes, encaminada al bien común, o sea vinculante para todos sus miembros" ${ }^{60}$.

La peculiaridad de esta teoría, insistimos, está en la fuente de la obligación, que no se encuentra en una coacción moral exterior al hombre sino en él mismo, en la exigencia de la naturaleza humana ${ }^{61}$. El mando del superior es una condición, claramente indispensable, y aún más, es condición de la obligación. Sin embargo, los límites de tal obligación son, sin duda alguna, los actos interiores, puesto que, en palabras de Vereecke, "le sanctuaire de la conscience reste donc inviolé» ${ }^{62}$.

El legislador -ya sea humano o eclesiástico- no atribuye ulterior fuerza vinculante a una norma que no sea la que la misma norma posee por su origen en la ley natural.

La función del legislador se limita a dar "vida" a dicha norma. La norma existe ya, independientemente del proceso formativo de la ley por la intervención de la autoridad, que la comunica y, por sí misma, la insinúa al inferior mediante un acto de imperium. Por este motivo es vinculante en conciencia. La obligación moral, al igual que su grado de fuerza, tiene su origen casi automáticamente en la ley natural ${ }^{63}$.

De ahí que la ley sea un praeceptum, un mando, una orden ${ }^{64}$. Las palabras praeceptum y obligación están estrechamente relacionadas, hasta el punto de decir que "De ratione legis est praeceptum superioris habentis publicam auctoritatem [...] ubi autem praeceptum est, obligatio aliqua debet esse" ${ }^{\text {"65 }}$.

El mandato es una conditio sine qua non para la existencia de la obligación, dado que debe ser conocido por los obligados. De esta manera el poder del legislador no sobrepasa ningún límite y el precepto emanado está jurídicamente constituido, al igual que la obligación, y goza de una existencia autónoma ${ }^{66}$.

Vázquez deja insatisfechas algunas preguntas filosófico-políticas relevantes, cuyas respuestas se pueden solo deducir, es decir: ¿cuál es la raíz última de la legitimización del poder?, ¿contiene una investidura divina, que sólo aparentemente pasa a través de la comunidad de los hombres? Si es posible que tal tema político, a pesar de haber encendido numerosos debates en aquellos años, acabará teniendo para el jesuita poco relieve, salvo en los términos según los cuales el hombre se asocia a otro

\footnotetext{
${ }^{60}$ Todescan, F., Lex, natura, beatitudo, op. cit., p. 169.

${ }^{61}$ Cfr. Vereecke, L., Conscience morale et loi humaine selon Gabriel Vazquez s.j., op. cit., p. 149.

62 Idem.

${ }^{63}$ Cfr. ibid., p. 568.

${ }^{64}$ Cfr. Vereecke, L., Conscience morale et loi humaine selon Gabriel Vazquez s.j., op. cit., p. 60.

${ }_{65}$ Vázquez, G., Commentariorum, ac disputationum in primam secundae S. Thomae, II, op. cit., d. 158, c. III, n.14, pp. 128-129.

${ }^{66}$ Cfr. Vereecke, L., Conscience morale et loi humaine selon Gabriel Vazquez s.j., op. cit., p. 62.
} 
hombre, en cuanto es tal su naturaleza racional y, además, se asocia directamente en forma monárquica o aristocrática. En conclusión, se puede decir que todo se centra en el problema de la legitimación del poder de la autoridad que dicta leyes. Que las leyes obliguen en conciencia me parece que asume un carácter casi consecuente, por no decir marginal. Los textos de Vázquez y las interpretaciones proporcionadas en apoyo de la reconstrucción del pensamiento del jesuita hacen hincapié, de manera coherente, en el vínculo expresado por la ley y en cuáles son los pasos lógicos llevados a cabo por el autor para alcanzarlos, pero, como ha sido dicho al inicio del presente parágrafo, hay una breve indicación sobre el tema puramente político de la elección de la forma de gobierno y sobre cómo se forma una comunidad, mientras que no existe una profundización autónoma.

La referencia totalizadora a la ratio como respuesta a todas las preguntas y, con ella, el rígido sistema descrito por Vázquez dejan al margen algo que pone en dificultad el sistema y que el jesuita no sabe explicar ni localizar completamente. El único punto de referencia del cual poder sacar consecuencias plausibles es solo el "suapte natura", el cual, lejos de dar una indicación sobre la índole de la naturaleza humana ${ }^{67}$, une de manera indisoluble la rectitud de la razón del hombre hacia el bonum, que se expresa plenamente en su naturaleza, sin duda alguna racional, con el obrar justo del hombre mismo ${ }^{68}$.

\footnotetext{
${ }^{67}$ No se puede esperar una consideración del hombre como naturalmente propenso al bien, como será el trazado por Ugo Grozio, ni naturalmente propenso al mal, como el de Niccolò Machiavelli o, más adelante, el de Thomas Hobbes.

${ }^{68}$ Es siempre en el suapte natura que se detectan o, mejor dicho, se manifiestan plenamente, los papeles que cada individuo desempeña en una comunidad; por tanto, también en la eventual comunidad política, cuya formación para Vázquez no asume ninguna importancia teórica, nace ya con roles bien definidos y completos.
} 


\section{REFERENCIAS BiBLIOGRÁFICAS}

Astrain, A., La historia de la Compañía de Jesús en la asistencia de España, Madrid, Administración de Razón y Fe, 1913.

Castro, C., Vida inédita del P. Gabriel Vázquez, ed. Arch. Teol. Granad., 37 (1974).

Cathrein, V., Moralphilosophie, Herder Friburgo de Brisgovia, 1911, I Band, 5B, 1.

Cruz Cruz, J., La esencia humana como regla autónoma del obrar moral, según Vázquez (s. XVI), en «Persona y Derecho: Revista de fundamentación de las Instituciones Jurídicas y de Derechos Humanos», 2013/2, vol. 6.

Faraco, C., Suapte natura. L'intrinseca forma razionale della natura: Gabriel Vázquez, Milano, FrancoAngeli, 2017.

Fellermeier, J., Begriff und Verpflichtung des positiven Gesetzes bei Gabriel Vazquez, en «Scholastik», 1940.

Fellermeier, J., Das Obligationsprinzip bei Gabriel Vazquez, Roma, Scuola Salesiana del Libro, 1939.

Garssen, H., Die Naturrechtslehre des Gabriel Vasquez, Göttingen, 1951.

Slovák, J., De conscientia morali apud Gabrielem Vazquez S.I., Romae, Pontificia Università Lateranense, 1971.

Sygut, M., Natura e origine della potestà dei vescovi nel Concilio di Trento e nella dottrina successiva, Roma, PUG, 1998.

Tessarolo, G., La nozione di soddisfazione e la necessità dell'incarnazione presso Gabriele Vasquez, Romae, PUG, 1942.

Todescan, F., Lex, natura, beatitudo, Padova, Cedam, 2014.

Todisco, O. Liberare la verità. Duns Scoto all'assalto della prigione di Dio, en "Giornale di metafisica» Ser. NS, vol. 30 (2008).

Vázquez, G. Commentariorum, ac disputationum in primam secundae S. Thomae, tomus secundus, Compluti, ex Officina Iusti Sanchez Crespo, 1605.

Vázquez, G. Commentariorum, ac disputationum in primam secundae $S$. Thomae, tomus primus, Compluti, ex Officina Ioannis Gratiani, 1614.

Vereecke, L., Conscience morale et loi humaine selon Gabriel Vazquez s.j., Tournai, Desclée \&Co Ed., 1957.

DOI: https://doi.org/10.15366/bp2021.26.012

Bajo Palabra. II Época. No26. Pgs: 239-254 